\title{
Automated Determination of the Power Required and Selection of Electric Motors for Forging Fly-Press Mechanisms
}

\author{
K. Karakoulidis \\ Department of Electrical Engineering, Eastern Macedonia and Trace Institute of Technology, Greece
}

Received 29 May 2015; Accepted 10 June 2015

\begin{abstract}
The current work deals with appropriate selection of electric motors for forging fly-press machines. To solve the equation of motion of the electric drive of these mechanisms characterized by impact (pulsating) load and presence of flywheel, numerical methods (calculus) have been used.
\end{abstract}

Keywords: induction motor, electric drive, forging fly-press machine.

\section{Introduction}

Particularities of mechanical and electrical equipment of forging fly-press machines with crank mechanism are discussed in Rachev [1], Rachev [2] and Rachev [3].

The kinematics scheme of crank forging fly-press is shown on Fig. 1 - given in Rachev [1]. The rotational movement from the electric motor 1 by means of wedge belt transmission 2 is turned over flywheel 3 , then by means of clutch 4 and toothed gearings 5 and 8 - to the crankshaft $7-$ given in Rachev [1]. The rotational movement by means of the crank mechanism is transformed into advanced movement of slide-block 6 . The use of belts, manufactured in rubber or plastic, offers a potential cost saving over other methods of transmission - given in Rachev [1].

The impact character of resisting moment leads to shock loading of the motor - a key feature in the operation of forging fly-press machines.

The change of resisting moment often happens with some frequency in which alternate idling (spent on rising and lowering the impact tool) and operation mode - punch (pressure) on forging - given in Rachev [2]. In order to equalize the load of the motor for the time of the cycle, in the kinematic scheme is placed a flywheel with large moment of inertia.

Summarizing it can be said that when the crank machinery is characterized in that during the deformation of the metal main job is performed not by the electric motor, but from the flywheel.

In leveling the load capacity those losses of electricity are reduced. For these reasons, an appropriate selection of the flywheel and the electric motor in forging fly-press machines is essential - Rachev [2].

* E-mail address: karakoul@teiemt.gr ISSN: 1791-2377 (C) 2015 Kavala Institute of Technology. All rights reserved.
The impact load causes fluctuations in the moment and the current of the motor. Furthermore, this leads to an increase of the variable loss of electric energy in the electric motor and power grid, as these losses are proportional to the value of the current squared.

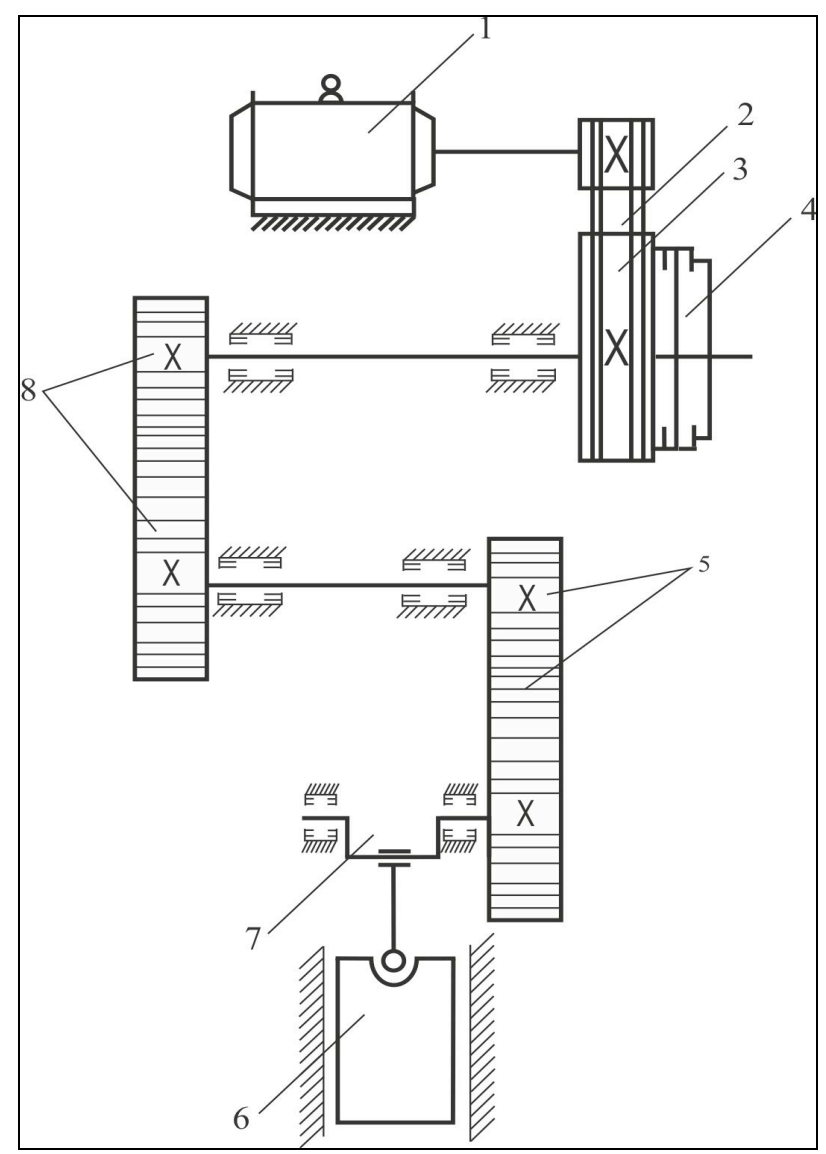

Fig. 1. Kinematics scheme of forging fly-press, 1 - electric motor; 2 wedge belt transmission; 3 - flywheel; 4 - clutch; 5, 8 - tooth gear; 6 - slide-block; 7 - crankshaft 


\section{Proper sizing of electric drive}

By means of the crank mechanism, occurring component of the kinematic chain is obtained reciprocating movement without reversing the motor. But reduced to the motor shaft resisting moment and moment of inertia depends on the angle of rotation of the crankshaft: $M_{\text {resist }}=f(\alpha)$ и $J=f(\alpha)$. This leads to an uneven (pulse) load of the motor and greatly complicates its selection - Karakoulidis [4].

In this case, the fundamental equation of motion takes the form - Karakoulidis [4]:

$M_{m o t}-M_{r e s i s t}=J \frac{d \varpi}{d t}+\frac{\varpi^{2}}{2} \cdot \frac{d J}{d \alpha}$

Rated power of the electric motors for specific mechanisms is chosen according to the expected load and mode of operation.

\subsection{Preliminary selection of the electric motor}

The average power of the electric motor may be determined from the formula - Karakoulidis [4]:

$P_{A V E}=M_{A V E} . \varpi_{A V E}$,

where: $M_{A V E}$ - average resistance moment of the mechanism reduced to the electric motor shaft; $\varpi_{A V E}$ average angular speed of the electric motor.

The starting point for calculating the electric drive is static resisting moment $M_{\text {resist }}=f(\alpha)$, reduced to the motor shaft for one operational cycle.

In a number of mechanisms the size of the static resisting moment is determined by the coordinate of the actuator. In this static resisting moment is a periodic function of the coordinate.

The average value of the resisting moment $M_{a v e}$ is Karakoulidis [4]:

$M_{\text {ave }}=\frac{\int_{0}^{2 \pi} M_{\text {resist }}(\alpha) \cdot d \alpha}{2 \pi}$

Using this average value the motor has to be selected: for small capacities - induction and for large capacities induction or synchronous. The power required will be Karakoulidis [4]:

$P^{\prime}=k \cdot M_{A V E} \varpi$,

where:

$k=1,1 \div 1,2$ - coefficient taking into account the dynamic loads; $\varpi$ - preliminary assigned angular speed of the electric motor.

Select electric motor with a rated power $P \geq P^{\prime}$ and angular speed $\varpi$ for continuous operation S1, taking into consideration the condition of starting and maximum torque. With this pre-selection is closed.

\subsection{Preliminary selection of moment of inertia required}

It is known that with an increase in electro-mechanical constant of the electric drive, the motor load in one cycle of operation is smoothed. It is therefore appropriate in the mechanisms of impact (pulsating) load to use the flywheel.

The required general, reduced to the motor shaft moment of inertia at induction motor drive is approximately determined by the formula - Karakoulidis [4]:

$J_{\text {req. }}=\frac{\int_{t_{N}}^{t_{\max }}\left(M_{\text {resist }}-M_{N}\right) \cdot d t}{\frac{\pi}{30} \cdot n_{N} \cdot \frac{s_{\max }}{1-0,5 \cdot s_{\max }}}$,

where:

$n_{N}$ - rated rotational frequency, $\min ^{-1} ; s_{\max }$ - critical (maximum) slip of the electric motor; $M_{N}$ - rated moment of the electric motor, $\mathrm{Nm}$;

Then the moment of inertia of the flywheel will be equal to - Karakoulidis [4]:

$J_{\text {FLYWHEEL }}=J_{\text {req. }}-J$

\subsection{Solving the equation of motion}

Once the dependencies $M_{\text {resist }}=f(\alpha), \quad J=f(\alpha)$ and $\frac{d J}{d \alpha}=f(\alpha)$ are definited we can solve the fundamental equation of motion Eq. 1.

A driving moment of an induction motor with sufficient accuracy can be determined using the formula of Kloss Karakoulidis [4]:

$M_{m o t}=2 M_{\max } \frac{\left(\varpi_{0}-\varpi\right) \cdot\left(\varpi_{0}-\varpi_{\max }\right)}{\left(\varpi_{0}-\varpi\right)^{2} \cdot\left(\varpi_{0}-\varpi_{\max }\right)^{2}}$,

where:

$M_{\text {max }}$ - maximum moment of the induction motor, Nm; $\varpi_{0}$ - synchronous angular speed, rad/s; $\varpi_{\max }$ - critical (maximum) angular speed, $\mathrm{rad} / \mathrm{s}$.

There is the relationship between angle of rotation of the crankshaft and the motor speed - Karakoulidis [4]:

$\frac{d \alpha}{d t}=\varpi_{\text {crankshaft }}=\frac{\varpi_{m o t}}{i}$

where $i$ - gear ratio of the reducer.

Considering that the fundamental equation of motion Eq. 1 can be converted into a system of two differential equations of the first order, namely - Karakoulidis [4]:

$\| \begin{aligned} & \frac{d \alpha}{d t}=\frac{\varpi}{i} \\ & \frac{d \varpi}{d t}=\frac{\left(M_{\text {mot }}-M_{\text {resist }}-\frac{\varpi^{2}}{2} \cdot \frac{d J}{d \alpha}\right)}{J}\end{aligned}$

Taking independent variable angle of rotation of the crankshaft is obtained - Karakoulidis [4]: 


$$
\| \begin{aligned}
& \frac{d t}{d \alpha}=\frac{i}{\varpi} \\
& \frac{d \Phi}{d \alpha}=\frac{i \cdot\left(M_{m o t}-M_{\text {resist }}-\frac{\Phi^{2}}{2} \cdot \frac{d J}{d \alpha}\right)}{J . \Phi}
\end{aligned}
$$

Solve the fundamental equation of motion allows you to find $\varpi=f(\alpha) ; \alpha=f(t) ; M_{m o t}=f(t)$.

Result of solving (10) are mathematical relationships: $\varpi=f(\alpha) ; \alpha=f(t) ; M_{\partial в}=f(t)$.

\subsection{Check the motor according to heating condition}

1. Solving the fundamental equation of motion with specified moment of inertia.

2. Determining the relationship $M_{m o t}=f(t)$.

3. Calculate the equivalent moment of the electric motor by means of the following formula - Vladimirov [5]:

$M_{e q}=\sqrt{\frac{\int_{0}^{t} M_{N}^{2} \cdot d t}{t_{c y c l e}}}$

4. The selection is correct, if $M_{e q} \leq M_{N}$, wherein it is necessary $M_{N} \geq M_{e q}>M_{N 1}$, where

$M_{N 1}$ - rated moment of the following catalog motor with less power - Stoyanov [6].

5. If $M_{e q}>M_{N}-$ select a new motor with more power.

\subsection{Algorithm of the program for determining the} required power and selection of electric motor

The block diagram of an algorithm for determining the power and the selection of the electric motor and the optimum moment of inertia of the flywheel of the electric drive of the crank mechanism with the reciprocating motion is given on Fig. 2 - Karakoulidis [4].

According to the block diagram shown, the setting of the optimal parameters of the electric drive becomes the method of successive approximations, such as the importance of the individual units is:

Block 1. Choose mechanism. From the main menu is selected mechanism with reciprocating movement of the actuator. In this case - forging fly-press mechanism.

Block 2. An input. Introduces input data specific to each mechanism.

Block 3. Preliminary determination of motor power in approximate method.

Block 4. Choosing motor by conditions: $P_{N}>P_{A V E}$ and conditions for starting, if necessary.

Block 5. In case of default of the conditions for the selection of the motor when there is not appropriate one in the catalog Stoyanov [6], a relevant message appears and suggests possible changes in the terms of assignment (for example: select another motor synchronous speed or to fill the catalog with new motors).
Block 6. Preliminary estimation of the moment of inertia of the electric drive by means of Eq. 5 .

Block 7. Solving the fundamental equation of motion.

Block 8. Determine whether the inertia moment of the system is optimal and if so not, in Block 9 is a correction of inertia moment and control returns to Block 7.

Block 10. Calculation of the equivalent moment of the motor by means of Eq. 11 .

Block 11. Check whether $M_{e q} \leq M_{N}$ and if so not, in

Block 12 is set the condition to seek a new motor with more power.

Block 13. Plot a graphs of performance of the electric drive in one cycle, namely:

$$
M_{\text {resist }}=f(\alpha) ; M_{\text {mot }}=f(\alpha) ; n_{\text {mot }}=f(\alpha) \text {; }
$$

Block 14. Output results of the calculations.

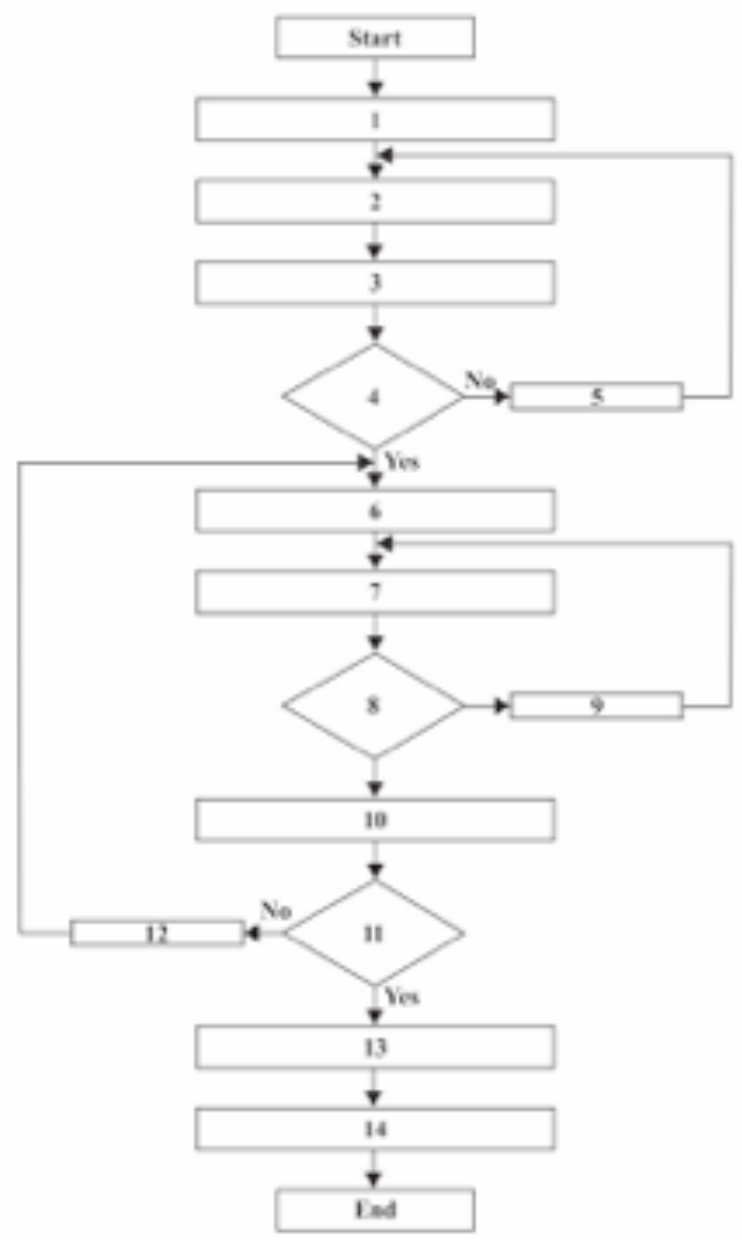

Fig. 2. Block diagram of an algorithm

The program calculates the resistance force, the moment and power of forging fly-press machines reduced to the motor shaft, selects a appropriate motor and checks according to permissible heating.

Input data in dialog mode are:

- crank arm radius, m;

- length of piston rod, m;

- distance to the center of gravity of the piston rod, m;

- mass of the piston rod, $\mathrm{kg}$;

- mass of the slider and operating tool, $\mathrm{kg}$; 
- synchronous rotational frequency;

- time for one cycle of operation, s;

- efficiency of the mechanism;

- maximum resistive force, $\mathrm{N}$;

- movement of the slider under the effect of the resistive force, $\mathrm{mm}$.

The program automatically creates files in the current folder in which record and store raw data for individual mechanisms. All information necessary for the program is displayed on the monitor through dialog windows and information lines and also when pressing the key reference F1. Return to the main menu from any place is done by pressing the key Esc.

Database for electric motors incorporates such a rated voltage of $400 \mathrm{~V}$ in the power range of $0.37 \div 250 \mathrm{~kW}$ series $\mathrm{AO}, \mathrm{AO} 2, \mathrm{AOP}, \mathrm{AOC}, \mathrm{AM}, 4 \mathrm{AO}, \mathrm{M}, \mathrm{MO}, \mathrm{MOM}$ and rated voltage $6 \mathrm{kV}$ in the power range of $500 \div 2500 \mathrm{~kW}$ series AP - Stoyanov [6].

Mechanical characteristics of the motors found in the catalog may be viewed through the "Mechanical characteristics" from the main menu. Characteristics were obtained by calculations using the formula of Kloss. It gives sufficiently accurate results for slips less than critical (maximum) one $-0<\mathbf{S}<\mathbf{s}_{\max }$. For slips greater than the critical one real depending $M_{\text {mot }}=f(s)$ does not match the calculated values. If necessary to print on printer output and results of calculations using standard printing options.

\subsection{Results obtained}

Tab. 1, Tab. 2 and Tab. 3 contain some of the results of the program work.

Table 1 Results obtained for fly-wheel inertia moment, gear ratio of the reducer, equivalent moment, duration of operating cycle

\begin{tabular}{|c|c|c|c|c|c|c|c|}
\hline \multirow{2}{*}{$\begin{array}{l}\mathrm{n}_{0} \\
\min ^{-1}\end{array}$} & \multicolumn{2}{|c|}{ Motor selected } & \multirow{2}{*}{$\begin{array}{l}\eta, \\
\%\end{array}$} & \multirow{2}{*}{$\begin{array}{c}\mathrm{J}_{\mathrm{FLYWHEE}} \\
\mathrm{L}, \mathrm{kgm}^{2}\end{array}$} & \multirow[b]{2}{*}{$\mathrm{i}$} & \multirow{2}{*}{$\begin{array}{c}\mathrm{M}_{\mathrm{EQ}}, \\
\mathrm{Nm}\end{array}$} & \multirow[b]{2}{*}{$\begin{array}{c}\mathrm{t}_{\text {cycle }} \\
, \mathrm{s}\end{array}$} \\
\hline & $\begin{array}{l}\mathrm{P}_{\mathrm{N}} \\
\mathrm{kW}\end{array}$ & Type & & & & & \\
\hline \multirow{4}{*}{750} & \multirow{4}{*}{$\begin{array}{c}3.0 \\
0\end{array}$} & $\begin{array}{c}\mathrm{AM} \\
132 \mathrm{M}-8\end{array}$ & $\begin{array}{c}80 . \\
0\end{array}$ & 0.3575 & 3 & $\begin{array}{c}36.1 \\
0\end{array}$ & $\begin{array}{c}0.2 \\
6\end{array}$ \\
\hline & & $\begin{array}{c}\mathrm{AO} 2132 \mathrm{M} \\
-8\end{array}$ & $\begin{array}{c}80 . \\
0\end{array}$ & 0.3709 & 3 & $\begin{array}{c}32.3 \\
1\end{array}$ & $\begin{array}{c}0.2 \\
6\end{array}$ \\
\hline & & $\mathrm{AO} 2-42-8$ & $\begin{array}{c}80 . \\
0\end{array}$ & 0.3712 & 3 & $\begin{array}{c}32.3 \\
1\end{array}$ & $\begin{array}{c}0.2 \\
6\end{array}$ \\
\hline & & $\begin{array}{c}\mathrm{AO} 2132 \mathrm{~S}- \\
6\end{array}$ & $\begin{array}{c}82 . \\
0\end{array}$ & 0.2395 & 4 & $\begin{array}{c}27.4 \\
2\end{array}$ & $\begin{array}{c}0.2 \\
6\end{array}$ \\
\hline \multirow[t]{2}{*}{$\begin{array}{c}100 \\
0\end{array}$} & $\begin{array}{c}3.0 \\
0\end{array}$ & $\begin{array}{c}\text { AM } \\
6\end{array}$ & $\begin{array}{c}82 . \\
0\end{array}$ & 0.2384 & 4 & $\begin{array}{c}27.7 \\
1\end{array}$ & $\begin{array}{c}0.2 \\
6\end{array}$ \\
\hline & & AO2-41-6 & $\begin{array}{c}82 . \\
0\end{array}$ & 0.2399 & 4 & $\begin{array}{c}27.1 \\
1\end{array}$ & $\begin{array}{c}0.2 \\
6\end{array}$ \\
\hline $\begin{array}{c}150 \\
0\end{array}$ & $\begin{array}{c}3.0 \\
0\end{array}$ & $\begin{array}{c}4 \mathrm{AO} \\
100 \mathrm{LL}-4 \mathrm{D}\end{array}$ & $\begin{array}{c}82 . \\
0\end{array}$ & 0.1971 & 7 & $\begin{array}{c}16.4 \\
2\end{array}$ & $\begin{array}{c}0.3 \\
0\end{array}$ \\
\hline $\begin{array}{c}300 \\
0\end{array}$ & $\begin{array}{c}2.4 \\
0\end{array}$ & AOC-42-2 & $\begin{array}{c}78 . \\
4\end{array}$ & - & $\begin{array}{l}1 \\
3\end{array}$ & 7.67 & $\begin{array}{c}0.2 \\
9\end{array}$ \\
\hline
\end{tabular}

Table 2 Results obtained for mean resisting moment and maximum resisting moment

\begin{tabular}{c|c|c|c}
\hline $\mathrm{n}_{0}, \min ^{-1}$ & $\mathrm{P}_{\mathrm{N}}, \mathrm{kW}$ & $\mathrm{M}_{\text {resist.AVE. }}, \mathrm{Nm}$ & $\mathrm{M}_{\text {resist. MAX., Nm }}$ \\
\hline 750 & 3.00 & 24.27 & 139.20 \\
1000 & 3.00 & 18.20 & 104.40 \\
1500 & 3.00 & 10.40 & 59.66 \\
3000 & 2.40 & 5.60 & 32.12 \\
\hline
\end{tabular}

Table 3 Technical data of motors selected - rated current, multiplicity of starting current, multiplicity of starting moment, multiplicity of maximum moment, rotor moment of gyration

\begin{tabular}{|c|c|c|c|c|c|c|c|}
\hline \multirow{2}{*}{$\begin{array}{c}\mathrm{n}_{0} \\
\min ^{-1}\end{array}$} & \multicolumn{2}{|c|}{ Motor selected } & \multirow{2}{*}{$\begin{array}{c}\mathrm{I}_{\text {nom }} \\
, \mathrm{A}\end{array}$} & \multirow{2}{*}{$\begin{array}{c}\mathrm{I}_{\mathrm{st}} / \\
\mathrm{I}_{\mathrm{no}} \\
\mathrm{m}\end{array}$} & \multirow{2}{*}{$\begin{array}{c}\mathrm{M}_{\mathrm{st}} / \\
\mathrm{M}_{\mathrm{no}} \\
\mathrm{m}\end{array}$} & \multirow{2}{*}{$\begin{array}{c}\mathrm{M}_{\max } \\
\mathrm{M}_{\text {nom }}\end{array}$} & \multirow{2}{*}{$\begin{array}{l}\mathrm{GD}^{2}, \\
\mathrm{kgm}^{2}\end{array}$} \\
\hline & $\begin{array}{l}\mathrm{P}_{\mathrm{N}}, \\
\mathrm{kW}\end{array}$ & Type & & & & & \\
\hline \multirow{4}{*}{750} & \multirow{3}{*}{$\begin{array}{c}3.0 \\
0\end{array}$} & $\begin{array}{c}\mathrm{AM} \\
132 \mathrm{M}-8\end{array}$ & 7.9 & 4.5 & 1.9 & 2.1 & 0.158 \\
\hline & & $\begin{array}{c}\mathrm{AO} 2132 \mathrm{M} \\
-8\end{array}$ & 8.0 & 5.4 & 1.5 & 1.5 & 0.162 \\
\hline & & AO2-42-8 & 8.0 & 5.0 & 1.5 & 1.5 & 0.160 \\
\hline & & $\begin{array}{c}\mathrm{AO} 2132 \mathrm{~S} \\
6\end{array}$ & 7.0 & 6.2 & 1.7 & 2.3 & 0.123 \\
\hline \multirow[t]{2}{*}{$\begin{array}{c}100 \\
0\end{array}$} & $\begin{array}{c}3.0 \\
0\end{array}$ & $\begin{array}{c}\text { AM 132S- } \\
6\end{array}$ & 7.1 & 5.8 & 2.2 & 2.4 & 0.126 \\
\hline & & AO2-41-6 & 7.0 & 6.1 & 1.7 & 2.2 & 0.123 \\
\hline $\begin{array}{c}150 \\
0\end{array}$ & $\begin{array}{c}3.0 \\
0\end{array}$ & $\begin{array}{c}4 \mathrm{AO} \\
100 \mathrm{LL}-4 \mathrm{D}\end{array}$ & 6.9 & 6.0 & 2.4 & 2.8 & $\begin{array}{c}0.0075 \\
2\end{array}$ \\
\hline $\begin{array}{c}300 \\
0\end{array}$ & $\begin{array}{c}2.4 \\
0\end{array}$ & AOC-42-2 & 6.2 & 5.5 & 2.8 & 2.8 & 0.040 \\
\hline
\end{tabular}

\section{Conclusion}

With increasing of the gear ratio of the reducer reduces the moment of inertia of the flywheel necessary $\mathrm{J}_{\mathrm{FLYWHEEL}}$, duration of operating cycle $t_{\text {cycle, }}$, is kept constant and the equivalent moment of the required electric motor decreases.

Optimal in terms of time for the conduct of one cycle of operation and minimum additional fly-wheel inertia moment is the option at $n_{0}=1000 \mathrm{~min}^{-1}$, ratio gearbox $\mathrm{i}=4$, motor type AO2-41-6 with rated power $\mathrm{P}_{\mathrm{N}}=3.00 \mathrm{~kW}$.

Logically, with the rise of the synchronous speed in the range of 750-3000 $\mathrm{min}^{-1}$ rotor moment of gyration decreases and increases the multiplicity of starting and maximum torque of the necessary electric motors.

With increasing synchronous speed in the range 750-3000 $\min ^{-1}$ decreased the average and maximum resisting moments.

\section{References}

1. Rachev S., K. Karakoulidis, L. Dimitrov. Dynamic Study of Forging Fly-Press driven by Electric Induction Motor. Proceedings of $12^{\text {th }}$ International Conference 'Research and Development in Mechanical Industry’ RaDMI 2012, Vrnjačka Banja, Serbia, 2012, vol. 2, pp. 1157-1164. ISBN 978-86-6075-037-4.
2. Rachev S., K. Karakoulidis. Estimation of Optimal Flywheel Masses of Forging Fly-Presses. Journal of Technical University Gabrovo, vol. 46, 2013, pp. 89-93. ISSN 1310-6686. (in Bulgarian)

3. Rachev S., K. Karakoulidis. Research on Energy losses in Electric Induction Motor for Forging Fly-Press Drive. Proceedings of 
XXII ${ }^{\text {nd }}$ International Conference 'Ecological Truth' EcoIst '14, Bor, Serbia, 2014, pp. 131-136. ISBN 978-86-6305-021-1.

4. Karakoulidis K. Automated Determining the Power Required and Slection of Electric Motors for Reciprocating Compressors. Information, Communication and Control Systems and Technologies, Rousse University 'Angel Kanchev', Bulgaria, 2014, ISSN 1314-7455.
5. Vladimirov P., Rachev S. Handbook for the Design of Electrical Euipment, University Publishing House 'Vasil Aprilov', Technical University - Gabrovo, 2008. ISBN 978-954-683-403-4. (in Bulgarian)

6. Stoyanov S., S. Pandurov. Desk book on Energetics, vol. 5, Sofia., ABC Tehnika, 1998. ISBN 954-8873-18-5. (in Bulgarian) 